Original Research Paper

\title{
Sosialisasi Rumput Laut (Eucheuma Cotonii) Hasil Kultur Jaringan di Desa Puulemo Kecamatan Poleang Timur Kabubaten Bombana
}

\author{
Oce Astuti ${ }^{1}$, La Sara ${ }^{2}$, Akhmad Mansur ${ }^{3}$, Ira $^{4}$ \\ ${ }^{1}$ Jurusan Budidaya Perairan, Fakultas Perikanan dan Ilmu Kelautan, Universitas Halu Oleo, Kendari, Indonesia; \\ ${ }^{2} J u r u s a n$ Manajemen Sumberdaya Perairan, Fakultas Perikanan dan Ilmu Kelautan, Universitas Halu Oleo, Kendari, \\ Indonesia; \\ ${ }^{3}$ Jurusan Agrobisnis Perikanan, Fakultas Perikanan dan Ilmu Kelautan, Universitas Halu Oleo, Kendari, Indonesia; \\ ${ }^{4}$ Jurusan Ilmu Kelautan, Fakultas Perikanan dan Ilmu Kelautan, Universitas Halu Oleo, Kendari, Indonesia
}

https://doi.org/10.29303/jpmpi.v3i2.953

Sitasi: Astuti, O., Sara, L., Mansur, A \& Ira. (2021). Sosialisasi Rumput Laut (Eucheuma Cotonii) Hasil Kultur Jaringan di Desa Puulemo Kecamatan Poleang Timur Kabubaten Bombana. Jurnal Pengabdian Magister Pendidikan $I P A, 4(3)$

\section{Article history}

Received: 28 Agustus 2021

Revised: 10 September 2021

Accepted: 12 September 2021

*Corresponding Author: La

Sara,

Jurusan Manajemen Sumberdaya Perairan, Fakultas Perikanan dan Ilmu Kelautan, Universitas Halu Oleo, Kendari, Indonesia;

Email:

lasara unhalu@yahoo.com

\begin{abstract}
Sosialisasi rumput laut (Eucheuma cottonii) hasil kultur jaringan ini merupakan salah satu kegiatan pengandian kepada masyarakat yang disatukan dengan KKN UHO, yang bertujuan untuk memberikan pembelajaran kultur jaringan rumput laut kepada mahasiswa sekaligus memberikan keterampilan kepada masyarakat pembudidaya terkait cara mengikat dan penempatan rumput laut yang tepat di perairan. Metode yang digunakan dalam kegiatan yaitu penyuluhan kepada masyarakat. Tahapan kegiatan yang dilakukan yaitu pembelajaran dan sosialisasi kepada masyarakat. Kegiatan pembelajaran dilakukan oleh mahasiswa sebelum terlibat langsung ke masyarakat. Kegiatan sosialisasi dilakukan oleh mahasiswa dan dosen kepada masyarakat khususnya pembudidaya rumput laut dan anak-anak SMPN 05 poleang timur. Hasil kegiatan menunjukkan bahwa tingkat partisipasi masyarakat cukup tinggi terutama anak-anak dan ibu-ibu rumah tangga yakni dengan terlibat secara langsung dalam kegiatan pelatihan dan sosialisasi.
\end{abstract}

Keywords: Rumput laut, kultur jaringan, Eucheuma cottonii

\section{Pendahuluan}

Kabupaten Bombana merupakan salah satu Kabupaten/kota di Sulawesi Tenggara yang memiliki potensi perikanan pantai dan laut yang cukup besar. Salah satu komoditi unggulan budidaya pantai yang memiliki pangsa pasar eksport, yaitu rumput laut (Eucheuma Cottonii). Rumput laut merupakan bahan dasar dalam industri makanan, kosmetik, farmasi, maupun sebagai bahan pendukung dalam industri lain, seperti industri: kertas, tekstil, pasta gigi, produk ikan atau daging, dan pupuk (Farid, 2008), dan rumput laut menjadi salah satu komoditas ekspor Indonesia yang diandalkan untuk pemasukkan devisa negara.
Indonesia memiliki $45 \%$ spesies rumput laut dunia dan merupakan produsen terbesar rumput laut jenis cottonii. Kadi dan Genisa, (1993) menyebutkan bahwa di Indonesia terdapat hingga 555 jenis rumput laut.

Kabupaten bombana memiliki potensi budidaya rumput laut seluas 3.076 ha dengan luas lahan yang telah termanfaatkan seluas 1.013 ha. Pembudidaya rumput laut di Kabupaten Bombana tersebar di 15 kecamatan dari 17 kecamatan pesisir. Jumlah petani rumput laut sekitar 1.163 RTP (Rumah Tangkap Perikanan) dengan produksi rumput laut basah sekitar 23.576 Ton dengan Produktivitas 33 Ton/ha berat basah. Produksi yang dihasilkan sampai saat ini masih tergolong rendah bila dibandingkan dengan potensi hasil yang bisa 
dicapai sekitar 96 Ton/ha berat basah. Puulemo merupakan salah satu desa yang berada di kecamatan poleang timur yang menjadi penghasil rumput laut (Eucheuma cottonii).

Kendala dalam budidaya rumput laut di Desa Puulemo adalah ketersediaan bibit rumput laut yang sesuai permintaan pasar internasional. Selama ini bibit rumput laut yang digunakan adalah bibit yang diproduksi secara vegetatif dari sisa hasil panen sebelumnya. Bibit tersebut memungkinkan epifit, parasit atau patogen terbawa kembali pada siklus budidaya selanjutnya sehingga dapat mengakibatkan penurunan produksi. Selain itu pemakaian bibit yang berulang dapat mengakibatkan umur bibit yang melebihi standar dan tidak ada perbaikan kualitas bibit. Penggunaan benih yang berulang pada satu lokasi yang sama dapat menyebabkan penurunan kualitas karagenan maupun pertumbuhan yang ditandai dengan pertumbuhan yang kurang maksimal (Yong et al., 2013).

Oleh karena itu keberadaan bibit rumput laut yang unggul dan berkualitas sangat penting. Sebagaimana pernyataan Sulistiani, et al., (2012) bahwa upaya peningkatan produksi rumput laut ini harus didukung karena ketersediaan benih berkualitas secara terus menerus diperlukan. Salah satu usaha yang dapat dilakukan untuk menghasilkan rumput laut yang unggul dan berkualitas adalah melalui hasil kultur jaringan (kultur kalus) menggunakan eksplan dari tallus rumput laut (Suryati et al., 2007). Kultur jaringan pada rumput laut adalah kultur eksplan (fragmen thallus) secara aksenik dalam media air laut artificial yang diberi zat pengatur tumbuh (ZPT) dan zat pengkaya yang dapat memberikan efek regenerasi. Deangan teknik kultur jaringan diharapkan dapat membantu menghasilkan rumput laut yang unggul, sehingga meningkatkan pemberian benih yang dibutuhkan untuk budidaya dan menghasilkan bibit yang seragam, tingkat pertumbuhan yang lebih tinggi dalam jumlah banyak namun dalam waktu singkat (Dawes dan Koch, 1991; Reddy et al., 2003). Tujuan kegiatan pengabdian adalah mensosialisasikan rumput laut (Eucheuma cottonii) hasil kultur jaringan kepada masyarakat pesisir di desa puulemo kecamatan poleang timur kabupaten bombana.

\section{Metode}

\section{Waktu dan Tempat}

Metode pelaksanaan kegiatan berupa sosialisasi pengenalan rumput laut (Eucheuma cottonii) hasil kultur jaringan kepada masyarakat. Kegiatan dilaksanakan pada tanggal 7 Agustus - 7 September 2021 di Desa Puulemo Kecamatan Poleang Timur Kabupaten Bombana Propinsi Sulawesi Tenggara.

\section{Metode Pelaksanaan}

Kegiatan sosialisasi disatukan dengan kegiatan KKN Universitas Halu Oleo. Tahapan pelaksanaan kegiatan meliputi pertama, kegiatan pembelajaran kultur jaringan rumput laut (Eucheuma cottonii) oleh mahasiswa berjumlah 15 orang di kampus FPIK UHO dan di PT.CESI (Center Exellent Of Seawead Indonesia) kolaborasi Pemda Kabupaten Bombana. PT CESI merupakan mitra FPIK UHO dalam kegiatan ini dimana PT CESI merupakan salah satu perusahaan yang bergerak di bidang kultur jaringan rumput Euchema cottoni di Kabupaten Bombana. Kegiatan ini bertujuan untuk memberikan informasi dan pengetahuan terkait kultur jaringan kepada mahasiswa sebelum berinteraksi langsung dengan masyarakat. Kedua, kegiatan sosisalisasi dengan melakukan kegiatan penyuluhan. Adapun rangkaian kegiatan penyuluhan yang dilakukan yaitu mengenalkan rumput laut (Eucheuma cottonii) hasil kultur jaringan kepada masyarakat. Memberikan pemahaman tentang apa itu rumput laut hasil kultur jaringan, manfaat dan kelebihannya dibandingkan bibit yang konvensional, cara mengikat rumput laut yang benar. Diakhir kegiatan diadakan lomba mengikat rumput laut (Eucheuma cottonii).

\section{Hasil dan Pembahasan}

\section{Kegiatan Pembelajaran Kultur Jaringan Rumput Laut (Eucheuma cottonii)}

Sebelum mahasiswa terlibat langsung dengan masyarakat, maka terlebih dahulu diadakan pembekalan pengetahuan. Pembekalan pertama berasal dari Dosen Penanggung jawab Lapangan (DPL) yang berlokasi di kampus FPIK UHO. Selanjutnya mahasiswa memperoleh pembekalan dari PT. CESI (Center Exellent Of Seawead Indonesia) kolaborasi Pemda Kabupaten Bombana. PT. CESI kolaborasi Pemda Kabupaten Bombana merupakan salah satu perusahaan yang bergerak di 
bidang kultur jaringan yang menjadi penyediaan bibit rumput laut (Eucheuma cottonii). Tujuan didirikanya untuk meningkatkan mutu dan kualitas dari rumput laut di kabupaten bombana. PT. CESI memiliki empat bangunan fasilitas yang di antaranya, dua bangunan asrama, satu bangunan Green House, dan satu bangunan laboratorium kultur jaringan.

Pembekalan di PT.CESI dilakukan di green house dan laboratorium. Di green house, mahasiswa diajarkan pemeliharaan dan aklimatisasi Eucheuma cottonii dari alam dan aklimatisasi bibit hasil kultur jaringan di keramba Jaring Apung (KJA). Aklimatisasi indukan dari alam dilakukan selama dua minggu. Minggu pertama, air laut diganti setiap hari hingga memasuki minggu kedua. Pada minggu kedua, pergantian air seminggu sekali dengan menambahkan pupuk. Kegiatan yang dilakukan di Mahasiswa juga diajarkan cara sterilisasi alat dan bahan, membuat media agar, pemotongan eksplan, uji sterilisasi eksplan, induksi kalus, regenerasi kalus embriogenik menjadi mikropropagul, regenerasi mikro propagul menjadi propagul (plantlet).

Setelah menjadi plantlet maka dilakukan uji kelayakan di green house sebelum dibawa ke keramba jaring apung (KJA). Di KJA dilakukan kembali aktimalisasi dengan memasukan kedalam tudung saji yang dilindungi jaring agar terhindar dari predator. Setelah aklimatisasi maka plantlet ditimbang untuk mengetahui berat awal bibit kemudian dilakukan pemeliharaan pada media longline selama 30 hari. Setelah melewati proses pemeliharaan maka bibit kultur jaringan dibawa ke kebun bibit untuk dipelihara selama 45 hari, setelah itu bibit ditebarkan ke masyarakat.
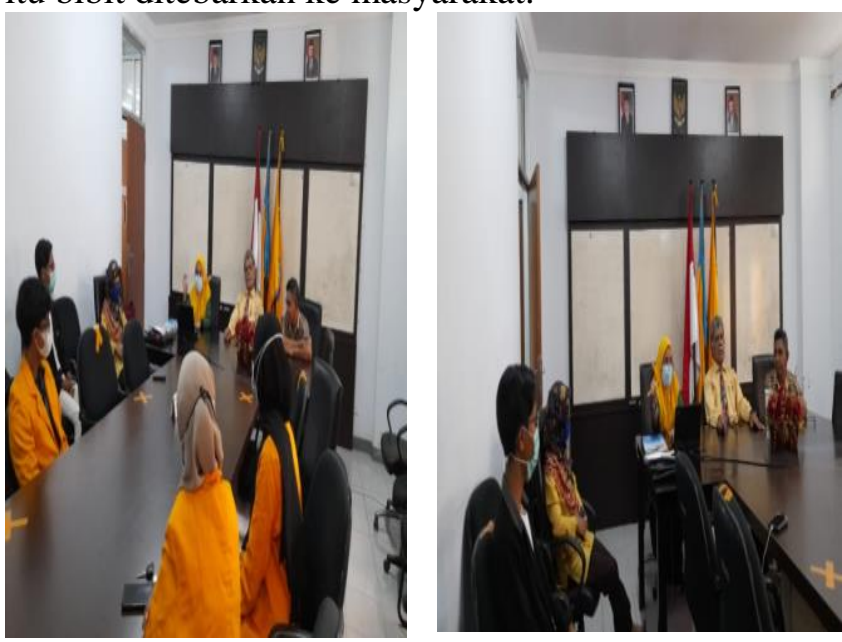
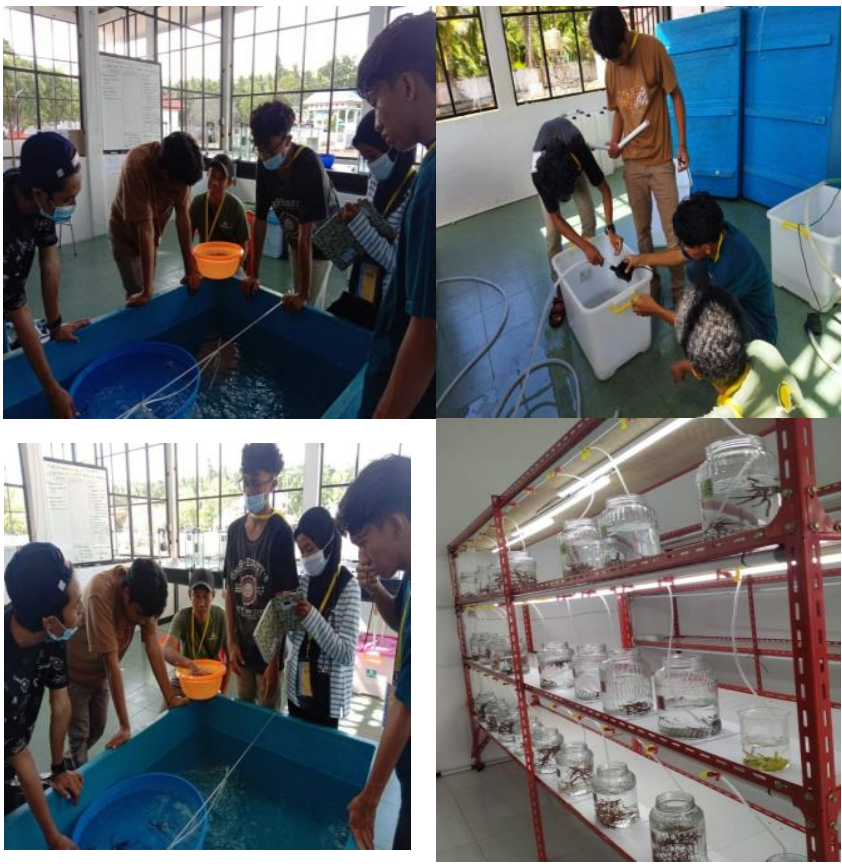

Gambar 1. Kegiatan pembekalan dan pembelajaran kultur jaringan

di green house dan laboratorium PT. CESI kolaborasi Pemba Kab. Bombana

Pemilihan sumber eksplan sangat penting dilakukan untuk menunjang keberhasilan induksi kalus. Sebagaimana menurut Hidayat (1994), seleksi bibit bertujuan agar diperoleh tanaman dengan pertumbuhan yang baik dan hasil aklimatisasi yang optimal. Pemilihan bibit Eucheuma cottonii yang digunakan berdasarkan SNI (Standar Nasional Indonesia). Menurut SNI, bibit rumput laut Eucheuma cottonii memiliki kriteria sebagai berikut: persyaratan kuantitatif, yaitu berumur 25-30 hari, talus minimal bercabang 3 , diameter talus utama minimal $0,5 \mathrm{~cm}$ dan seragam, berat per rumpun 50-10 g, sedangkan persyaratan kualitatif, yaitu talus tampak cerah dan segar, bersih dari kotoran, organisme penempel dan lumut, bebas penyakit, talus tidak luka dan patah, bertunas runcing dan bentuk proporsional (BSN, 2011).

\section{Sosialisasi Rumput Laut (Eucheuma cottonii) Hasil Kultur Jaringan Kepada Masyarakat}

Selama ini bibit yang digunakan oleh pembudidaya rumput laut masih berasal dari pengembangan vegetatif dengan cara menyisikan thalus dari hasil budidaya. Keterampilan dalam menyeleksi bibit yang baik menjadi pembatas bagi sebagian masyarakat pembudidaya, sehingga hasil 
produksi menjadi kurang optimal. Melalui kegiatan pengabdian diharapkan masyarakat dapat lebih mengetahui tentang rumput laut hasil kultur jaringan yang memiliki beberapa kelebihan dibandingkan dengan bibit rumput laut konvensional antara lain memiliki performa yang baik, termasuk lebih adaptif dan pertumbuhan yang lebih cepat.

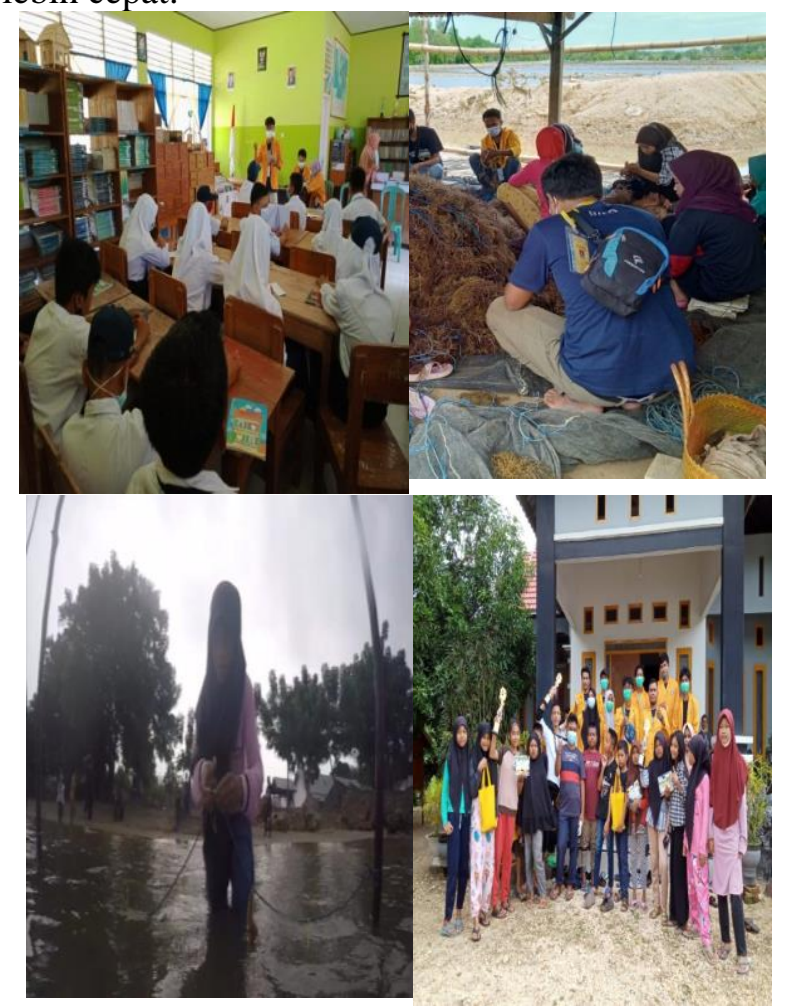

Gambar 2. Kegiatan sosialisasi rumput laut (Eucheuma cottonii) kepada masyarakat

Kegiatan sosailisasi dilakukan melalui penyuluhan kepada pembudidaya rumput laut dan Sekolah Menengah Pertama (SMP). Kegiatan sosialisasi dilakukan di lokasi pembudidaya rumput laut dan SMPN 05 poleang timur. Tujuannya adalah untuk menambah wawasan para pembudidaya rumput laut dan siswa tentang rumput laut, kultur jaringan serta manfaat rumput laut. Selain itu untuk menambah minat anak-anak akan rumput laut, maka diadakan kegiatan lomba mengikat rumput laut, yang diikuti oleh anak-anak sekolah menengah pertama. Kegiatan lomba berlangsung cukup meriah karena dirangkai dengan kegiatan tujuh belas agustus.
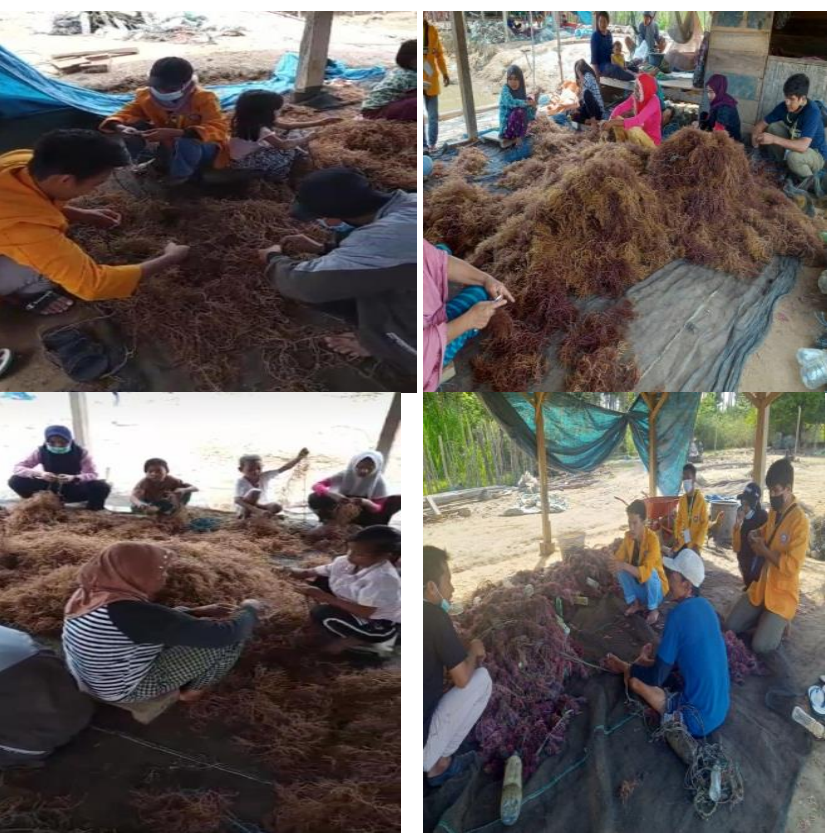

Gambar 3. Pelatihan mengikat rumput laut

Kegiatan lain yang dilakukan dalam rangka sosialisasi rumput laut hasil kultur jaringan yaitu kegiatan pelatihan cara mengikat dan posisi peletakan yang tepat di perairan. Karena cara mengikat rumput laut dan penempatannya di perairan akan mempengaruhi pertumbuhan dan kelangsungan hidup rumput laut. Kegiatan ini diikuti oleh para pembudidaya rumput laut dan anak-anak. Cara mengikat rumput laut yang baik yaitu dengan mengikat bibit rumput laut dengan posisi tenggelam atau masuk kedalam air diperkirakan kedalaman sekitar 10-15 cm, agar tidak mudah kena panas matahari dan kena kotoran yang berada di permukaan air. Suhu yang tinggi menyebabkan bibit rumput laut mudah kena penyakit.

\section{Kesimpulan}

Kegiatan pengabdian ini berjalan sesuai dengan perencanaan berupa kegiatan pembelajaran, kegiatan pelatihan serta kegiatan sosialisasi rumput laut (Eucheuma cottonii) kultur jaringan rumput laut. Kegiatan diikuti oleh pembudidaya rumput laut dan anak-anak sekolah tingkat pertama. Tingkat partisipasi masyarakat cukup tinggi terutama anak-anak dan ibu-ibu rumah tangga yakni dengan terlibat secara langsung dalam kegiatan pelatihan dan sosialisasi. 


\section{Daftar Pustaka}

BSN. 2011. Bibit Rumput Laut Kotoni.

Dawes, C. J. 1981. Marine Botany. New York (US): John Willey \& Sons.

Farid, Akhmad. 2008. Studi lingkungan perairan untuk budidayarumput laut (Eucheuma cottonii) di Perairan Branta, Pamekasan, Madura. Jurnal Penelitian Perikanan. Vol. 11 (1): $1-6$.

Reddy, C. R. K., Kumar, G. R. K, Shiddhanta, A. K and Tewari, A. 2003. In Vitro Somatic Embryogenesis and Regeneration of Somatic Embryos from Pigmented Callus of $\mathrm{K}$. alvarezii (Doty) Doty (Rhodophyta, Gigartinales). J. Phycol. Vol. 39:610-616.

Sulistiani, E., Soelistyowati, DT., Alimuddin and Yani, S.A. 2012. Callus induction and filaments regeneration from callus of cottonii seaweed (Kappaphycus alvarezii (Doty)) collected from Natuna Islands, Riau Islands Province. Biotropia. Vol. 19: 103-14.

Suryati, E dan Mulyaningrum, S. R. H. 2007. Regenerasi Rumput Laut K. alvarezii (Doty) Melalui Induksi Kalus dan Embrio dengan Penambahan Hormon Perangsang Tumbuh Secara In Vitro.J. Ris. Akuakultur. Vol 1: 3945.

Yong, W. T. L., Ting, S. H., Chin, W. L., Rodrigues, K. F and Anton, A. 2011. In Vitro Micropropagation of EucheumaSeaweeds. 2nd International Conference on Biotechnology and Food Science. IPCBEE. Vol. 7: 58-60 